\title{
CHEMICAL CHARACTERISTICS OF THE L-GLUTAMATE RECEPTOR ON THE ONCHIDIUM NEURON ${ }^{1}$
}

\author{
MASAKATSU KATO, ${ }^{2}$ YUTAKA OOMURA, JURO MARUHASHI, AND NOBUAKI SHIMIZU \\ Department of Physiology, Faculty of Medicine, Kyushu University, Fukuoka 812, Japan
}

Received May 27, 1982; Revised September 21, 1982; Accepted September 30, 1982

\begin{abstract}
Application of L-glutamate (L-glu) to particular neurons (G-H cells) in the esophageal ganglia of Onchidium produced hyperpolarization associated with an increase in $\mathrm{K}^{+}$permeability. The reversal potential $\left(\mathrm{E}_{\text {rev }}\right)$ for this response, was $-60 \mathrm{mV}$. The $\mathrm{ED}_{50}$, an indicator of affinity between L-glu and its receptive site, was $5.3 \mathrm{~mm}$, and the Hill coefficient $n$, an indicator of cooperativity, was 2 . Other chemicals, structurally analogous to L-glu, were also examined on G-H cells. The responses of Laspartate were similar to those of $\mathrm{L}$-glu with respect to $\mathrm{E}_{\mathrm{rev}}$, $\mathrm{ED}_{\mathrm{bu}}$, and $n$. However, the $\mathrm{G}-\mathrm{H}$ cells responded differently to D-glutamate (D-glu) and kainic acid. The D-glu response had an $\mathrm{E}_{\mathrm{rev}}=-37.5$ $\mathrm{mV}, \mathrm{ED}_{50}=29.4 \mathrm{mM}$, and $n=1$; that of kainic acid had an $\mathrm{E}_{\mathrm{rev}}=0 \mathrm{mV}, \mathrm{ED}_{50}=1.5 \mathrm{mM}$, and $n=1$. L-glutamine and GABA elicited very small responses, amplitudes of which were less than $10 \%$ of the L-glu response.

The structure-activity relationship between L-glu and its analogues, estimated from $\mathbf{E}_{\mathrm{rev}}, \mathrm{ED}_{50}$, and Hill coefficient during each drug application, indicates that the presence of $\alpha-\mathrm{NH}_{2}, \alpha-\mathrm{COOH}$, and $\gamma$-COOH groups is essential for the L-glu response and that the response characteristics may be closely related to the relative positions of these groups.
\end{abstract}

It has been found by Oomura et al. (1974) that a particular type of neuron, the G-H cell, which possesses two types of chemically sensitive membrane areas, exists in the ganglion of Onchidium, a marine pulmonate mollusc. One responds to $\mathrm{L}$-glutamate (L-glu) with a $\mathrm{K}^{+}$ permeability increase, which causes sustained hyperpolarization. The other produces short lasting hyperpolarization caused by a temporary $\mathrm{Cl}^{-}$permeability increase in response to acetylcholine. The receptive mechanism of the $\mathrm{L}$-glu receptor on the membrane of the G-H neurons, however, has not been fully elucidated. To learn more about the molecular structure of the L-glu receptive site, we have studied the structure-activity relationship of the L-glu response in Onchidium G-H cells. We report here that $\alpha-\mathrm{NH}_{2}, \alpha-\mathrm{COOH}$, and $\gamma-\mathrm{COOH}$ groups of L-glu are all essential, and the relative positions of these groups are important for the interaction with L-glu receptive sites.

\footnotetext{
${ }^{1}$ We thank Profs. C. Edwards and N. Akaike for help in preparation of this manuscript. This work was partly supported by Grants 311408, $387047,421815,448103,520967,577075$, and 587035 from the Ministry of Education, Science and Culture.

${ }^{2}$ To whom correspondence should be addressed at his present address: Department of Physiology, Institute of Endocrinology, Gunma University, Maebashi 371, Japan.
}

\section{Methods}

Esophageal ganglia were excised from the Onchidium verruculatum, which is similar to Aplysia and living on the rocky seashore in the southern part of Japan. The connective tissue which covers the ganglia was removed using microforceps. 'The preparation was then fixed to the bottom of a lucite chamber having a main chamber volume of $0.4 \mathrm{~cm}^{3}$ by five threads tied to appropriate connectives. The chamber was perfused continuously with artificial sea water between 18 and $22^{\circ} \mathrm{C}$ at a flow rate of about $1 \mathrm{ml} / \mathrm{min}$. Two glass capillary electrodes were inserted into a single neuron. One electrode was filled with $3 \mathrm{~m} \mathrm{KCl}$ for recording membrane potential and the other with $0.5 \mathrm{M} \mathrm{K}_{2} \mathrm{SO}_{4}$ for applying current across the cell membrane. The d.c. resistances of these electrodes ranged from 10 to 20 megohms. The indifferent electrode was a silver plate covered with agar sea water and immersed in the bathing solution.

The recording electrode was connected to a field effect transistor (FET) differential preamplifier with a high input impedance, and the input membrane conductance was measured by the voltage drop across the membrane produced by square current pulses ( $1 \mathrm{sec}$ duration at 0.1 $\mathrm{Hz}$ ). The return current from the indifferent electrode was measured by connecting it to the virtual ground of 
an operational amplifier, which had a 1 megohm feedback resistor. The outputs of the amplifiers were connected to a dual beam oscilloscope and to a two channel pen recorder. The technique for the voltage clamp of the membrane potential was similar to that described elsewhere (Oomura and Tomita, 1961).

The artificial normal sea water contained (mM): 459.6 $\mathrm{NaCl}, 9.6 \mathrm{KCl}, 10.4 \mathrm{CaCl}_{2}, 48.5 \mathrm{MgCl}_{2}$. The $\mathrm{pH}$ of sea water was kept at 7.5 with $\mathrm{HEPES}-\mathrm{NaOH}$ or Tris-HCl. In $\mathrm{Na}^{+}$substitution experiments, $\mathrm{NaCl}$ was replaced with isotonic Tris- $\mathrm{Cl}, \mathrm{MgCl}_{2}$, or glucosamine- $\mathrm{HCl}$.

The L-glu agonists were L-aspartate, D-glutamate (Dglu), kainic acid, L-glutamine, L-asparagine, and $\gamma$-aminobutyric acid (GABA). The L-glu antagonists were DL$\alpha$-aminopimelic acid, 2-amino-4-phosphonobutyric acid, L-glutamate- $\gamma$-methyl ester, L-glutamine, L-asparagine, D-tubocurarine, picrotoxine, atropine, and hexamethonium. The drugs were diluted with sea water to the appropriate concentration just before use. The experiments were carried out at room temperature. The results were confirmed with at least five neurons.

The G-H cells are located in the right ganglion of a pair of pleural ganglia of the esophageal ganglia and are indicated conventionally by the numbers $6,7,9$, and 10 (Oomura et al., 1974) (Fig. 1). The average soma diameter of these cells was $160 \pm 51 \mu \mathrm{m}(n=30$, mean $\pm \mathrm{SD})$.

\section{Results}

The effect of L-glu agonists. The resting membrane potential of $30 \mathrm{G}-\mathrm{H}$ cells immersed in normal sea water ranged from -30 to $-53 \mathrm{mV}$, with a mean of $-40.5 \pm 6.3$ (SD) $\mathrm{mV}$. These cells usually fired spontaneously with frequency at 0.5 to $1 \mathrm{~Hz}$. The amplitude of action potential was about $80 \mathrm{mV}$.

The responses to L-glu agonists are shown in Figure 2. Ten millimolar L-glu produced a hyperpolarization (Fig. $2 A$ ) associated with an increase in $\mathrm{K}^{+}$conductance (Ooumura et al., 1974). L-Aspartate, having a side chain one carbon shorter than L-glu's, also produced hyperpolarization associated with an increase in $\mathrm{K}^{+}$conductance (Fig. $2 B$ ). The response of the optical isomer $\mathrm{D}$-glu was a complex of the persistent hyperpolarization and depolarization (Fig. 2C). Replacement of external $\mathrm{Na}^{+}$by Tris suppressed the depolarizing phase of the $\mathrm{D}$-glu response (Fig. 2D). Kainic acid, which has a hetero ring, produced a depolarization with a desensitization (Fig. 2, $E$ to $H$ ). If the membrane potential was held at around $-40 \mathrm{mV}$ by an inward current, kainic acid still clearly increased the membrane conductance (Fig. $2 F$ ). Replacement of external $\mathrm{Na}^{+}$partly suppressed the depolarization as well as the conductance increase caused by kainic acid (Fig. $2 G$ ). In contrast, both L-asparagine, which lacks the $\beta$-COOH group of L-aspartate, and L-glutamine, which lacks the $\gamma$-COOH group of $\mathrm{L}$-glu, elicited very small hyperpolarizing responses in comparison to L-glu (Fig. 2, $H$ and $I$ ). GABA, which lacks the $\alpha$-COOH group of $\mathrm{L}$-glu, had two phases (Fig. 2.J), consisting of an early transient hyperpolarization with an increase in $\mathrm{Cl}^{-}$conductance and a late persistent hyperpolarization with an increase in $\mathrm{K}^{+}$ conductance (Oomura et al., 1979, 1982). The G-H cell was 10 times less sensitive to GABA than to L-glu.

The dose response curves to each agonist are shown in Figure 3, in which the conductance changes were normalized by the membrane conductance change $(\triangle \mathrm{Gm})$ of $50 \mathrm{~mm}$ L-glu. $\triangle \mathrm{Gm}$ is as follows: $\triangle \mathrm{Gm}=\mathrm{Gm}$ in agonist - Gm in normal sea water. The responses to both L-glu and $L$-aspartate were similar, except that the maximum conductance change for L-aspartate was less than that for L-glu. The responses to $\mathrm{D}$-glu and kainic acid differed from those to L-glu. $\mathrm{ED}_{50}$ was then measured. This is the agonist concentration at which one-half of the maximal conductance change was produced and is an indicator of the affinity between agonist and its receptive site. The $\mathrm{ED}_{50}$ was $5.3 \mathrm{~mm}$ for the L-glu and L-aspartate response and 29.4 and $1.5 \mathrm{~mm}$ for $\mathrm{D}$-glu and kainic acid, respectively (Table I). These differences are also seen in the

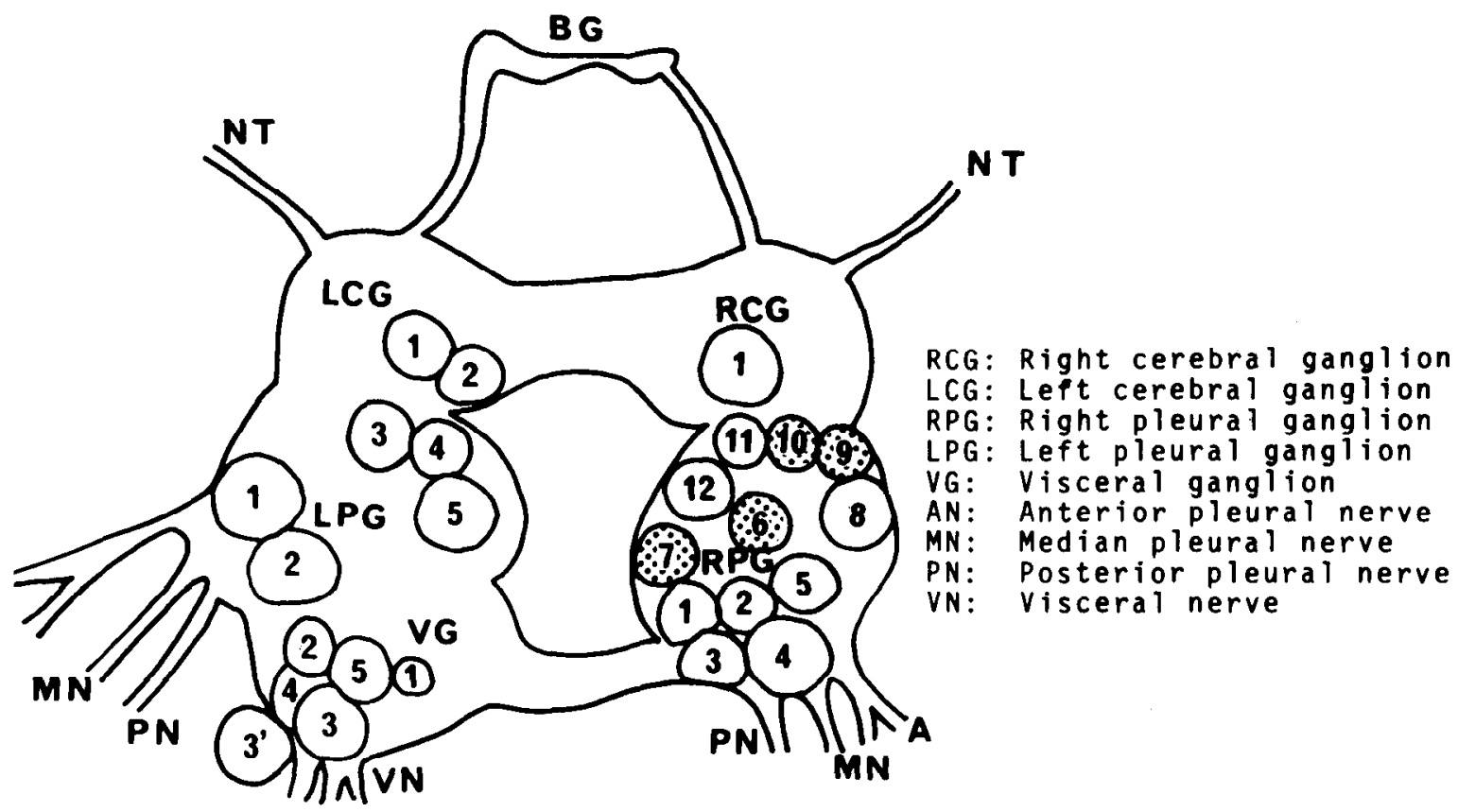

Figure 1. Dorsal view of the Onchidium esophageal ganglia. G-H cells (6, 7, 9, and 10 of right pleural ganglion) were used in this experiment. 
Hill plot shown in Figure 4. The Hill coefficient $n$, determined from the slope of the line, was 1.9 for the L-glu response and 2.3 for the L-aspartate response, and $n$ was 1.0 for both the D-glu and the kainic acid responses (Table I).
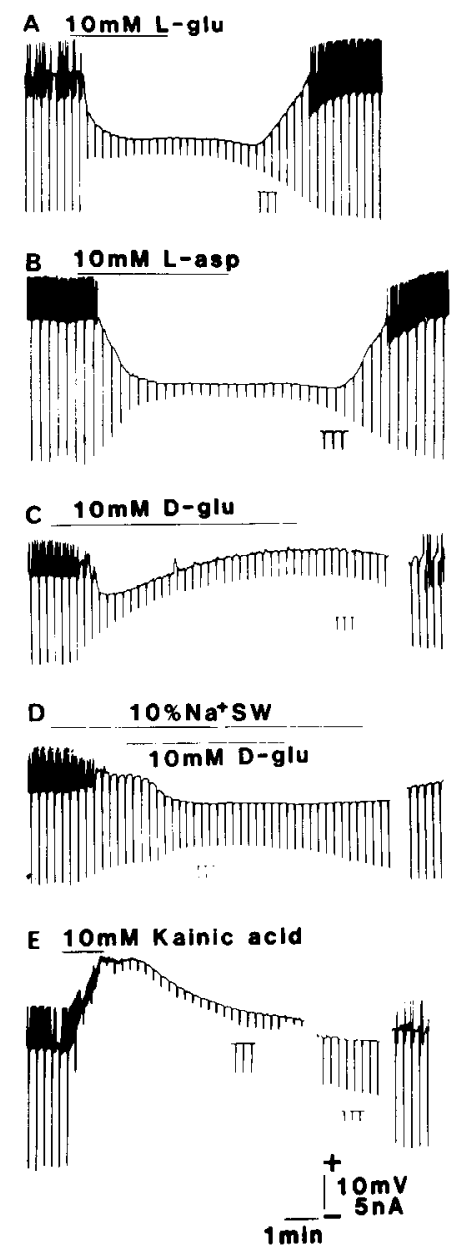

The reversal potentials $\left(\mathrm{E}_{\text {rev }}\right)$ of each agonist were determined under the voltage clamp condition. The holding potential was $-50 \mathrm{mV}$, and a clamp pulse was $1 \mathrm{sec}$ with various step voltages. The clamp currents were measured at the end of each pulse. The V-I relationship

F $10 \mathrm{mM} \mathrm{KaInlc} \mathrm{acld}$
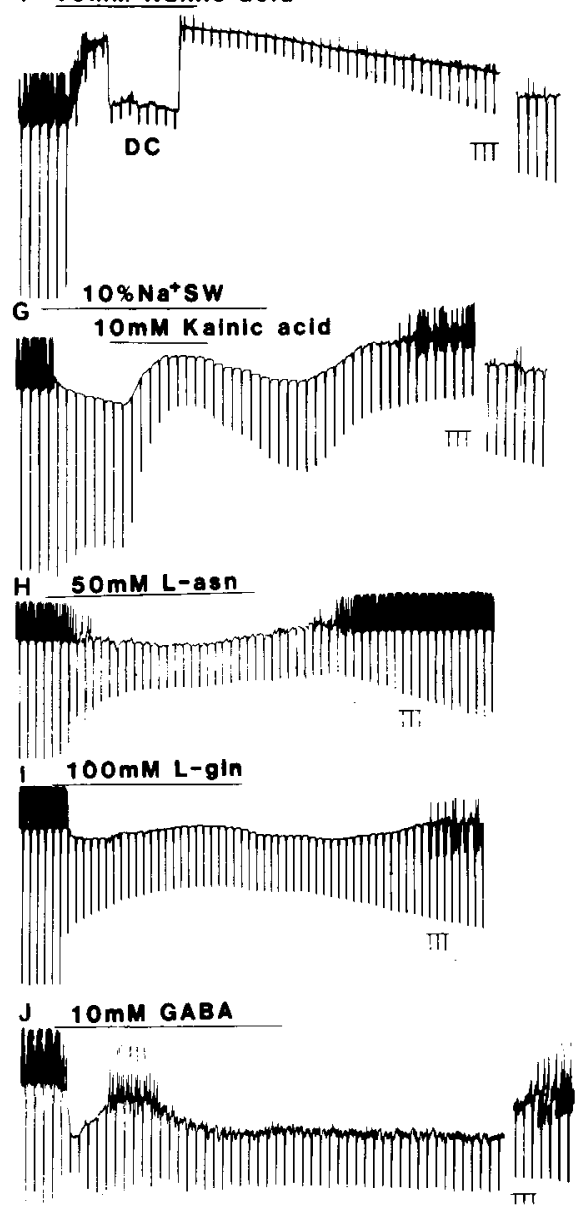

Figure 2. Effect of L-glu agonists to G-H cells. Resting membrane potential of each trace, -40mV. Upward deflexion, action potential. Amplitude of action potential reached $80 \mathrm{mV}$ but recorded smaller because of low frequency characteristics of pen write recorder. Downward deflexion, membrane potential change caused by intracellular inward rectangular current pulse with duration of $1 \mathrm{sec}$. Small downward deflexion at lower right of each trace, current intensity. Bar of each trace, period of agonist application. Period without the bar, perfused with artificial sea water. L-glu, L-glutamate; L-asp, L-aspartate; D-glu, D-glutamate; L-asn, Lasparagine; L-gln, L-glutamine; GABA, $\gamma$-aminobutyric acid; $10 \% \mathrm{Na}^{+} \mathrm{SW}, 10 \% \mathrm{Na}^{+}$sea water; $D C$, intracellular direct current application.

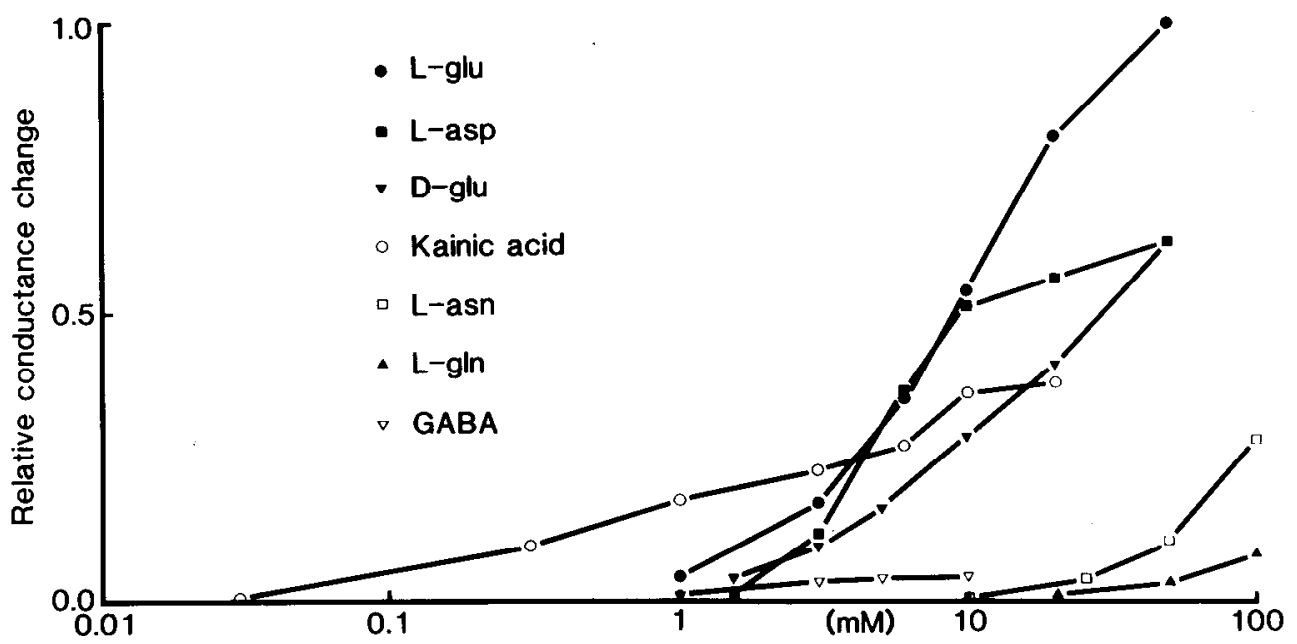

Figure 3. Dose response curve of L-glu agonists. Ordinate, membrane conductance change $(\Delta \mathrm{Gm})$ normalized with that of 50 mM L-glu. Abscissa, agonist concentrations. 
TABLE I

Effect of L-glu agonists and antagonists

Upper: Effects of L-glu agonists. $\mathrm{ED}_{50}$, agonist concentration to produce $50 \%$ of maximum response. $n$, Hill coefficient. $\mathrm{E}_{\mathrm{rev}}$, reversal potential. $\mathrm{H}$, hyperpolarization. D, depolarization. Gm, increase in membrane conductance. Lower: Effect of $\mathrm{L}$-glu antagonists. Bar under "Effect" indicates ineffective.

\section{L-glu Agonist}

\begin{tabular}{|c|c|c|c|c|c|c|}
\hline Agonist & EDso (mM) & $n$ & Erev(mV) & Response Typ & & Ionic Mechanism \\
\hline L-glu & 5.3 & 2 & -60 & Persistent $\mathrm{H}$ & $\mathrm{Gml}$ & $K^{+}$ \\
\hline L-asp & 5.3 & 2 & -60 & Persistent $\mathrm{H}$ & $\mathrm{Gm} \mathrm{I}$ & $K^{+}$ \\
\hline D-glu & 29.4 & 1 & -38 & Persistent $H, D$ & $\mathrm{Gm} 1$ & $\mathrm{Na}^{+}, \mathrm{K}^{+}$ \\
\hline Kainic Acid & 1.5 & 1 & 0 & $D$ (desensitization) & $\mathrm{Gm} 1$ & $\mathrm{Na}^{+}$,Others \\
\hline L-gln & $\longrightarrow$ & - & - & Weak H & $\mathrm{Gml}$ & $\longrightarrow$ \\
\hline L-asn & - & - & - & Weak $\mathrm{H}$ & $\mathrm{Gm}$ I & 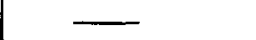 \\
\hline
\end{tabular}

\section{L-glu Antagonist}

\begin{tabular}{|c|c|c|}
\hline Antagonist & Concentration(mM) & Effect \\
\hline DL- $\alpha$-aminopimelic Acid & 10 & - \\
\hline 2-amino-4-phosphono- & & \\
\hline butyric Acid & 10 & \\
\hline $\begin{array}{l}\text { L-glutamate- } \gamma- \\
\text { methylester }\end{array}$ & 20 & - \\
\hline Gly & 50 & - \\
\hline$L-g \mid n$ & 10 & - \\
\hline L-asn & 10 & - \\
\hline d-tubocurarine & 1 & $\longrightarrow$ \\
\hline Picrotoxin & 2 & - \\
\hline Atropine & 5 & - \\
\hline Hexamethonium & 5 & - \\
\hline
\end{tabular}

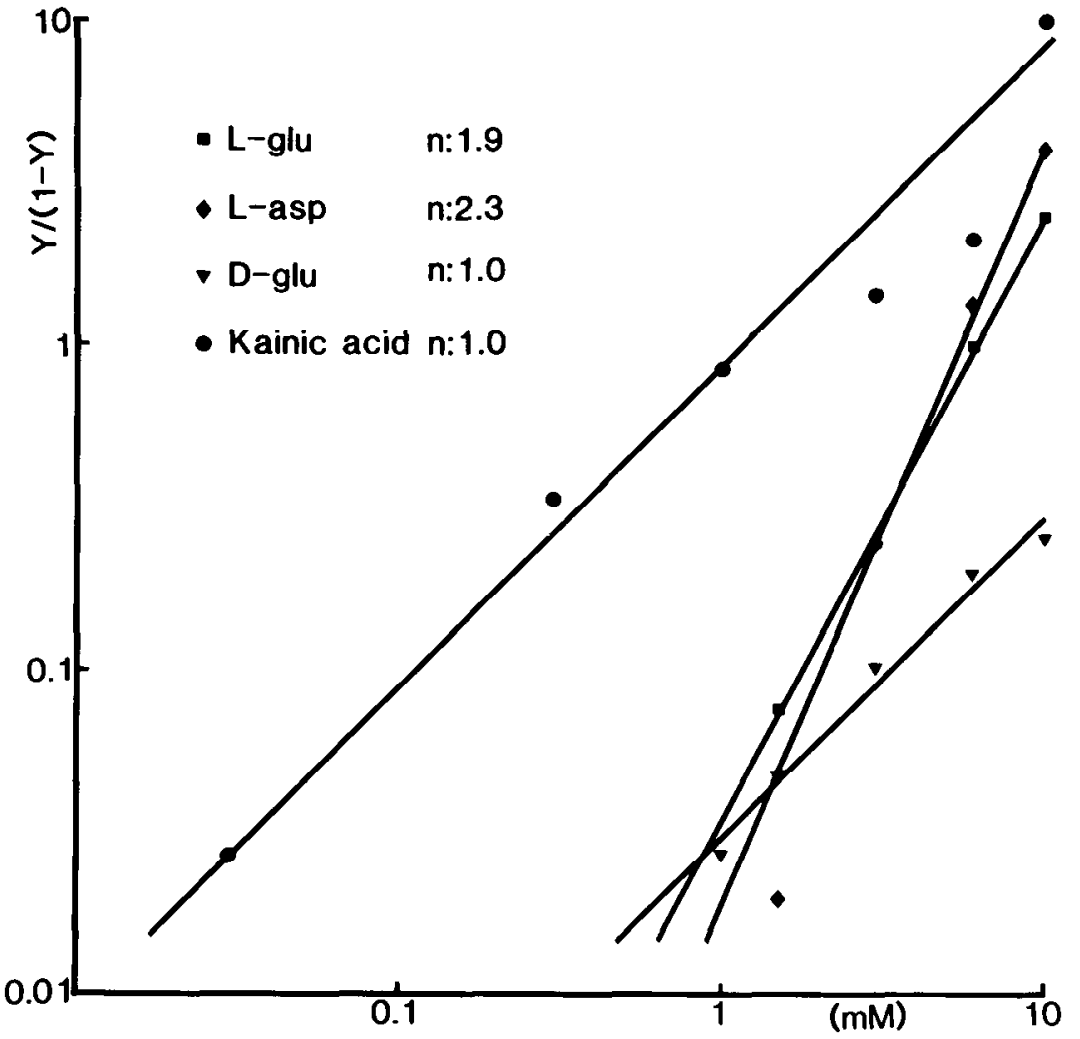

Figure 4. Hill plot of L-glu agonists. Ordinate, calculated with $\mathrm{Y}=\triangle \mathrm{Gm} / \triangle \mathrm{Gmax}$. $\triangle \mathrm{Gm}$, membrane conductance change produced by agonist. $\triangle \mathrm{Gmax}$, maximum membrane conductance change. Abscissa, agonist concentration. $n$, Hill coefficient. 
in normal sea water was nonlinear because of the slow persistent inward current activating around $-60 \mathrm{mV}$ and lower. $\mathrm{E}_{\mathrm{rev}}$ was determined by the crossover point of the V-I relationship in normal sea water and in that with an agonist. In the case of L-glu, L-aspartate, and D-glu, $\mathrm{E}_{\text {rev }}$ 's were directly determined, but $\mathrm{E}_{\mathrm{rev}}$ for kainic acid was determined by the extrapolation. Because of the extrapolation, the estimated value might be lower than the real. The $\mathrm{E}_{\text {rev }}$ for L-glu and L-aspartate was $-60 \mathrm{mV}$ (Fig. $5 A$, $B)$. $E_{\text {rev }}$ for the D-glu was $-37.5 \mathrm{mV}$, and for kainic acid it was estimated to be about $0 \mathrm{mV}$ (Fig. $5 C$ and $D$ ). These effects of agonists are summarized in Table I.

The effect of $\mathrm{L}$-glu antagonists. The effects of $20 \mathrm{~mm}$ L-glutamine on the L-glutamate response are shown in Figure 6. L-glutamine itself slightly increased the membrane conductance but did not antagonize the L-glu re-

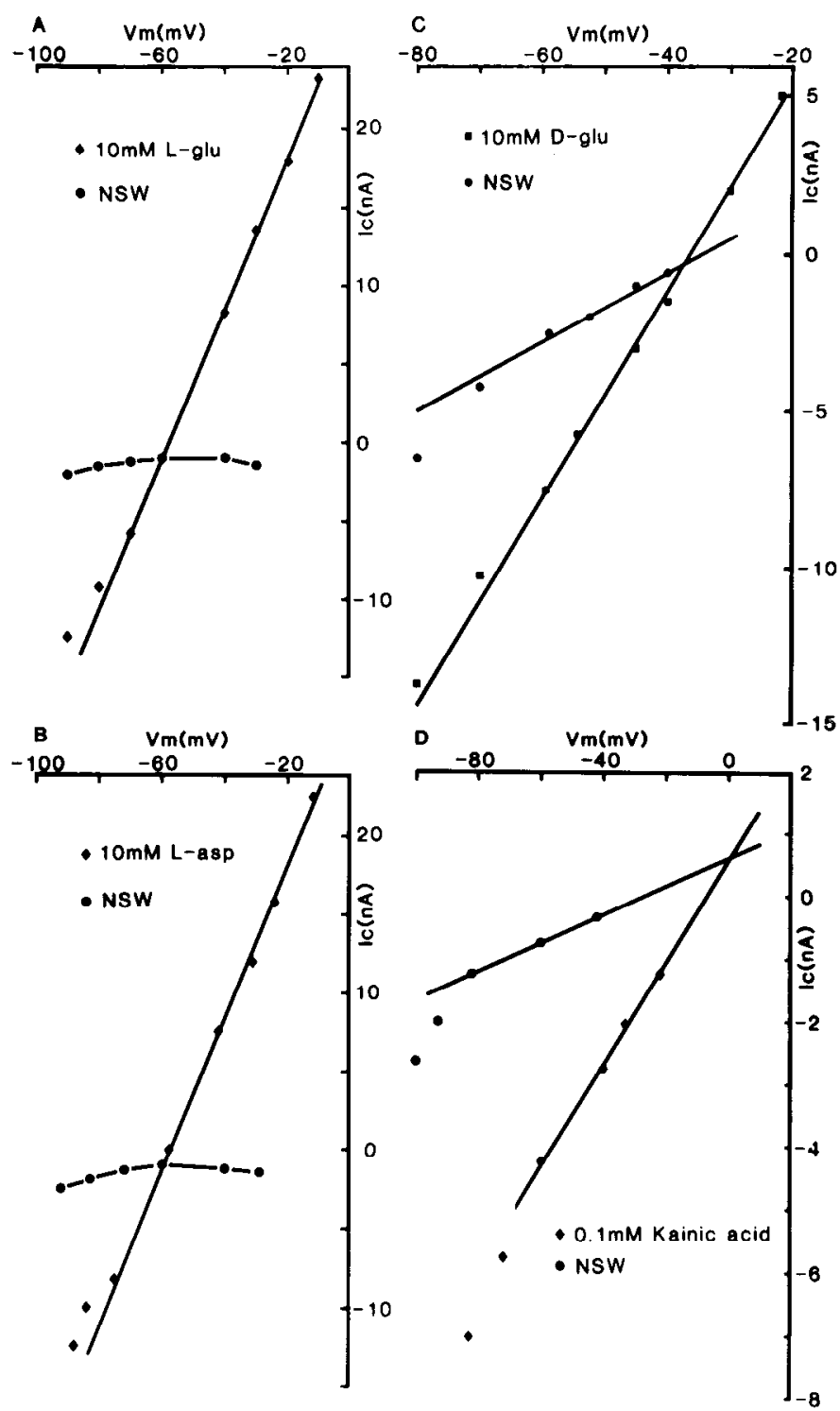

Figure 5. Reversal potential of L-glu agonists. Ordinate, membrane current $(I c)$ under the voltage clamp condition. Abscissa, voltages of clamp pulse ( $\mathrm{Vm}$ ). Holding potential, -50 $\mathrm{mV}$. Clamp pulse duration, 1 sec. Data of Ic were taken at the end of each pulse. Reversal potentials, determined from the cross points of V-1 curves in normal artificial sea water (NSW) and in agonists. sponse. Glycine, as well as I,-asparagine, produced weak responses, but neither antagonize the L-glu response.

L-Glutamate- $\gamma$-methyl ester inhibits the L-glu response in crustacean end plate (Lowagie and Gerschenfeld, 1974), and 2-amino-4-phosphonobutyric acid suppresses the L-glu response in locust muscle (Kerkut et al., 1975). However, both $10 \mathrm{~mm}$ 2-amino-4-phosphonobutyric acid and $20 \mathrm{mM}$ L-glutamate- $\gamma$-methyl ester had no effect on the L-glu responses of the G-H cells. DL- $\alpha$-Aminopimelic acid has been known to suppress reversibly the L-glu response of Helix neuron (Piggott et al., 1975), but at 10 $\mathrm{mm}$ it did not antagonize the L-glu response (Fig. 7). Table I summarizes the above results and lists several other compounds found to be without effect.

\section{Discussion}

Neuronal receptors have been suggested by De Robertis (1971) to have the following characteristics: $(i)$ the receptor should be a macromolecule essentially located in the subsynaptic membrane; (ii) it should be a protein intimately bound or built into the lipoprotein structure of the membrane; (iii) it should show high affinity for binding the natural endogenous transmitters and a specific competition with drugs that act as agonists or antagonists; and (iv) such macromolecules should be capable of undergoing some kind of reversible change when they react with the transmitter in order to account for the translocation of ions through the membrane and the subsequent bioelectrical response. Furthermore, the receptor is considered to be composed with subunits of receptive sites and to mediate ion permeability (Swan and Carpenter, 1975). An acetycholine (ACh) receptor, which can be isolated and purified, has five subunits, two of which interact with ACh (Heidmann and Changeux, 1978). The chemical nature of ACh receptors has been gradually clarified (Heidmann and Changeux, 1978). But other receptors are hard in their purification, and little is known about their chemical nature, although the kinetics and the pharmacology of their responses have been analyzed in detail (Dudel, 1977; Lester and Peck, 1979; Takeuchi and Takeuchi, 1964, 1972; Peper et al., 1975; Werman, 1969).

Although amino acids have various forms in solution, they presumably have to have a certain conformation in correspondence to the receptive sites to bind to a receptor. In this research the action of $\mathrm{L}$-glu was similar to that of L-aspartate whose relative positions of two $\alpha$-and $\gamma$ - $\mathrm{COOH}$ groups and one $\alpha-\mathrm{NH}_{2}$ group can be identical with those of $\mathrm{L}$-glu in certain conformations, although the side chain of L-aspartate is one carbon shorter than that of L-glu. The optical isomer D-glu, which is a mirror image of L-glu, cannot have these three groups in the same relative positions as $\mathrm{L}$-glu in any conformation. DGlu elicited a quite different response from that of L-glu (Fig. 2, C and D). Thus D-glu may act on different receptors than L-glu does. On the other hand, glycine, Lglutamine, and L-asparagine, which do not have a $\mathrm{COOH}$ group corresponding to the $\gamma-\mathrm{COOH}$ group of L-glu but do have the $\alpha$-COOH and the $\alpha-\mathrm{NH}_{2}$ groups, produced very weak responses at corresponding concentrations (Fig. 2, $H$, and $I$ ) and did not antagonize the L-glu response (Fig. 6). This fact implies that the $\gamma-\mathrm{COOH}$ group of L-glu is essential to activate L-glu receptors. 

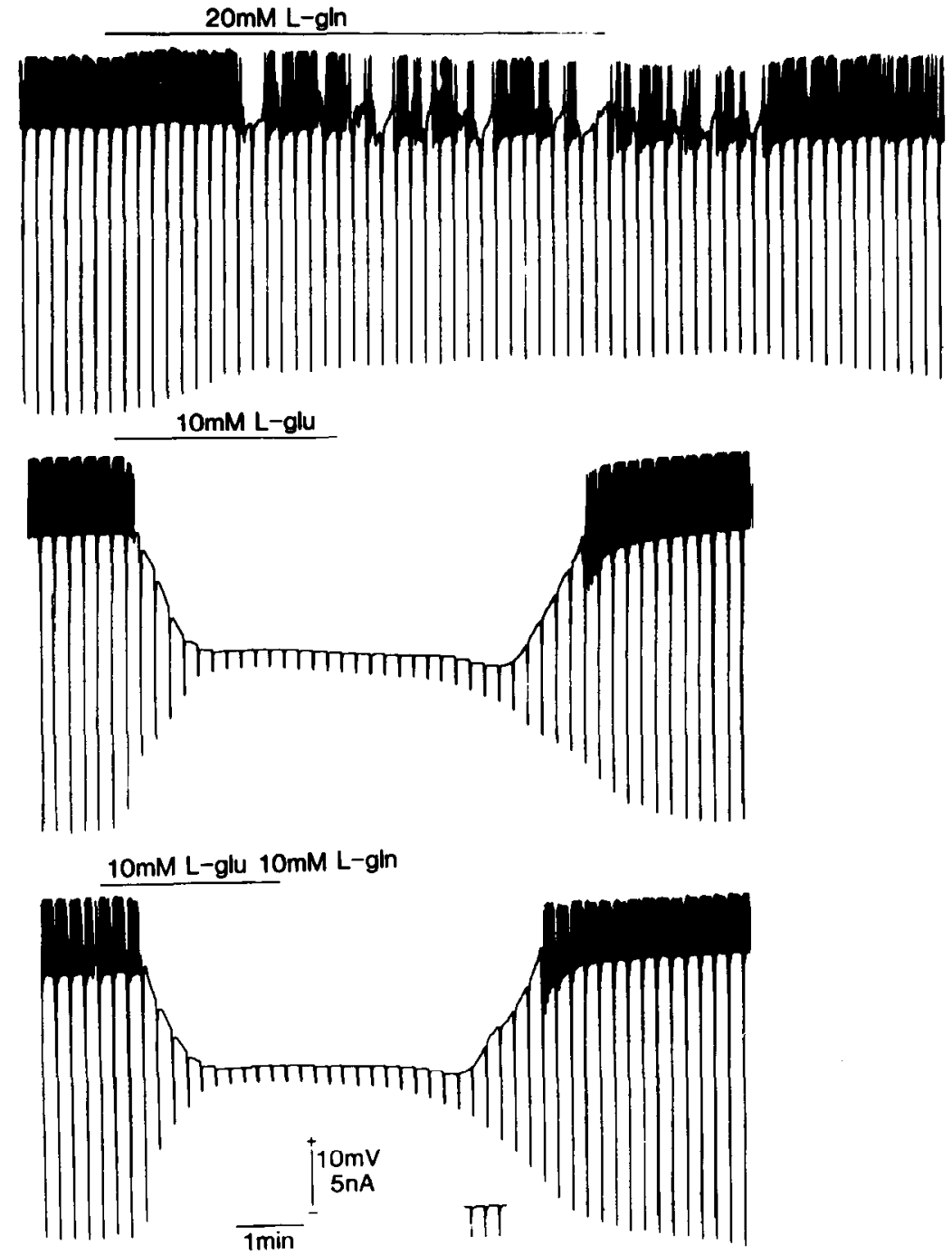

Figure 6. Effect of L-glutamine. Upper, $20 \mathrm{~mm} \mathrm{L-gln.} \mathrm{Middle,} 10 \mathrm{~mm} \mathrm{L-glu.} \mathrm{Lower,} \mathrm{L-glu} \mathrm{plus} \mathrm{L-gln.} \mathrm{L-gln} \mathrm{did} \mathrm{not} \mathrm{suppress} \mathrm{L-glu}$ response.

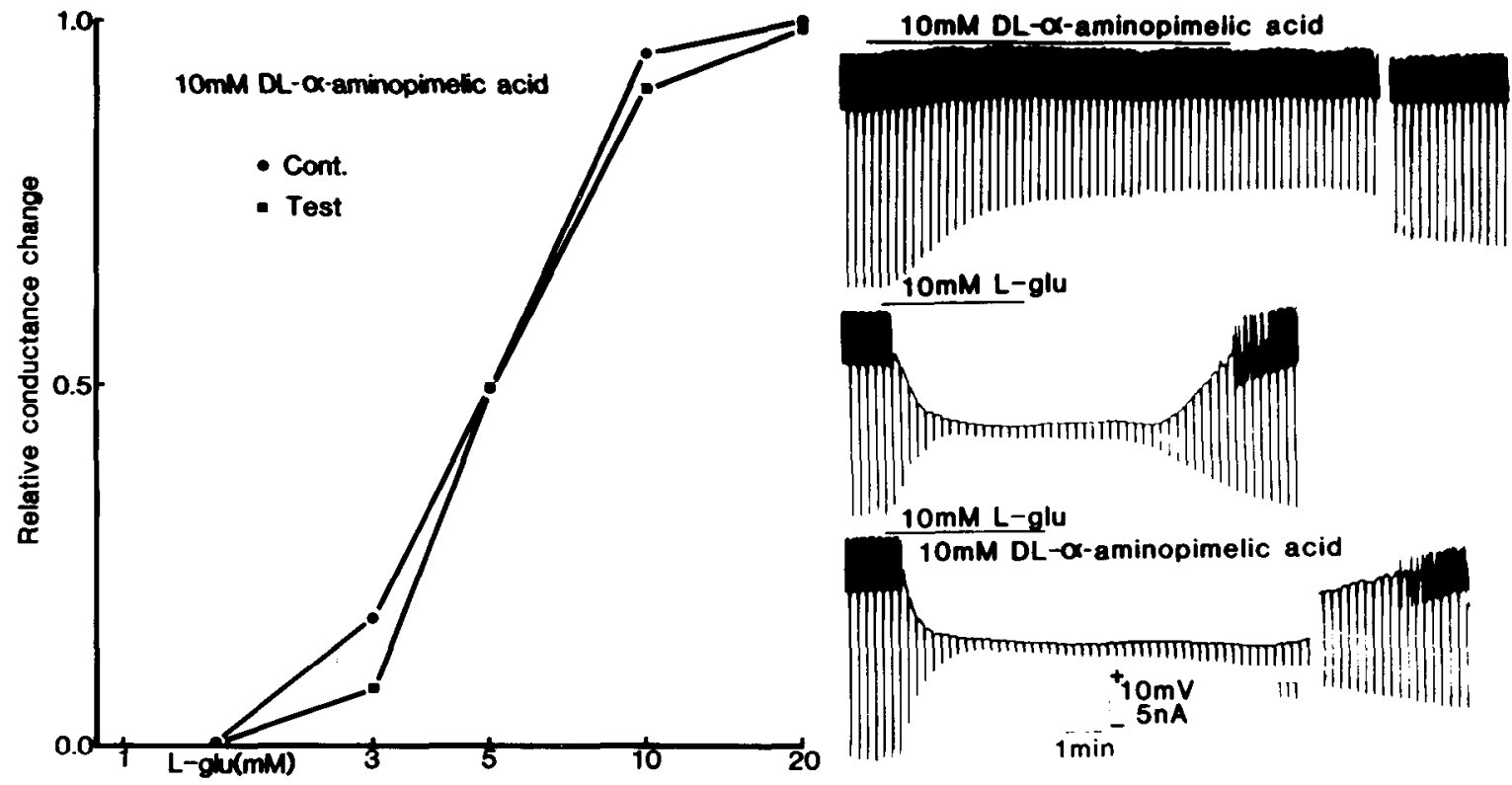

Figure 7. Effect of DL- $\alpha$-aminopimelic acid. Left, L-glu dose-response curve. 9 , control. $\mathbf{0}, 10 \mathrm{mM}$ DL- $\alpha$-aminopimelic acid. Ordinate, relative conductance change normalized by $20 \mathrm{~mm}$ L-glu. Abscissa, agonist concentrations. Right, upper, $10 \mathrm{~mm}$ DL- $\alpha$ aminopimelic acid. Middle, $10 \mathrm{mM}$ L-glu. Lower, L-glu plus DL- $\alpha$-aminopimelic acid. DL- $\alpha$-aminopimelic acid did not suppress Lglu response. 
GABA, which lacks the $\alpha$-COOH group of $\mathbf{L}$-glu, elicited a very small response with an amplitude less than $10 \%$ that of the L-glu response. From these results, the $\alpha-\mathrm{NH}_{2}$, $\alpha$-COOH, and $\gamma$-COOH groups of L-glu seem to be necessary for the interaction between L-glu and its receptive site. Furthermore, the relative positions of these groups may be important, because the action of $\mathrm{D}$-glu differed from that of L-glu.

The form of L-aspartate, on the other hand, corresponds to the folded form of L-glu. L-Aspartate and L-glu both elicited a hyperpolarization with an increase in $\mathrm{K}^{+}$ conductance. The Hill coefficient, $n$, the indicator of the degree of cooperativity, and $\mathrm{ED}_{50}$, the indicator of the affinity, were the same for both compounds (Fig. 4). Thus it is likely that L-glu and L-aspartate interact with the same receptive site. Therefore, the steric arrangement of L-glu which reacts with the receptive site is also the folded form, and the distance is $2.6 \AA$ between $\alpha-\mathrm{NH}_{2}$ and $\gamma$-COOH groups, $3.8 \AA$ between $\alpha-\mathrm{COOH}$ and $\gamma-\mathrm{COOH}$ groups, and $2.6 \AA$ between $\alpha-\mathrm{NH}_{2}$ and $\alpha$ - $\mathrm{COOH}$ groups. At physiological $\mathrm{pH}$ these three groups are electrically charged. Thus the receptive site may be composed of two positively charged and one negatively charged sites separated by about $2.6 \AA$ from each other.

Kainic acid, which has a hetero ring, is structurally rigid. The distances between the ring- $\mathrm{NH}_{2}$ group and the two $\mathrm{COOH}$ groups are relatively stable and their relative positions are identical to those of an extended form of $\mathrm{L}$ glu. The distances are $4.6 \AA$ between ring $\mathrm{NH}_{2}$ and one $\mathrm{COOH}$ group, $2.6 \AA$ between the $\mathrm{NH}_{2}$ and the other $\mathrm{COOH}$ group, and $3.6 \AA$ between two $\mathrm{COOH}$ groups. The response of kainic acid was a depolarization with an increase in $\mathrm{Na}^{+}$conductance. This was different from the L-glu response (Fig. $2, E, F$, and $G$ ). Kainic acid may act on receptors different from L-glu receptors.

The structure-activity relationship of I-glu receptors on Helix neurons has been also studied by Piggott et al. (1975). Their object was to classify L-glu receptors into those that mediate depolarization and those giving hyperpolarization. They also suggested three electrically charged sites for the receplive sile of L-glu, but they discussed only the distance between $\alpha-\mathrm{NH}_{2}$ and $\gamma-\mathrm{COOH}$ groups. According to their findings, the distances between the two sites are $2.6 \AA$ for the receptor mediating depolarization and $4.6 \AA$ for the hyperpolarizing response.

The reasons for these discrepancies between the present results and those of Piggott et al. cannot be explained at this time. Further investigations are necessary to settle this question.

Various drugs have been reported to antagonize the Lglu response in molluscan neurons and insect end plates (Nistri and Constanti, 1979). Atropine and picrotoxin antagonized the L-glu response in Helix neurons (Piggott et al., 1977) but not in Onchidium G-H cells. Since these drugs have no charged groups, it is unlikely that they interact directly with the receptive sites of L-glu, but they may antagonize the L-glu response by acting at sites near the receptive sites of L-glu. In this regard, the environmental structure around the receptive sites of Onchidium L-glu receptors might differ from that in Helix neurons and insect end plates. $d$-Tubocurarine antagonized L-glu response in Helix neurons (Piggott et al., 1977). Since $d$-tubocurarine and hexamethonium have two positively charged groups, these drugs might interact with negatively charged sites of L-glu receptors. But they were ineffective in Onchidium G-H cells. Thus molecules, having only positively charged groups, may not interact with the receptive sites of L-glu. L-Glutamate- $\gamma$-methyl ester antagonized L-glu response in crustacean end plate (Lowagie and Gerschenfeld, 1974). This drug is structurally similar to the neutral amino acid, Lglutamine, which lacks the $\gamma-\mathrm{COOH}$ group. As mentioned under "Results" (Fig. 6), neutral amino acids were almost ineffective as agonists or antagonists in Onchidium G-H cells. The ineffectiveness of L-glutamate- $\gamma$-methyl ester on Onchidium G-H cells again indicates that the $\gamma$ $\mathrm{COOH}$ group of $\mathrm{L}$-glu is essential for interaction between L-glu and its receptive site. DL- $\alpha$-Aminopimelic acid and 2-amino-4-phosphonobutyric acid antagonized L-glu response in Helix neurons (Kerkut et al., 1975), and insect end plates (Cull-Candy et al., 1976). These two drugs have structures similar to that of L-glu. They have two negatively charged groups and one positively charged group. DL- $\alpha$-Aminopimelic acid has the side chain of four carbons, which is two carbon atoms longer than that of L-glu and is the only difference from L-glu. DL- $\alpha$-Aminopimelic acid is able to take a conformation similar to the folded form of L-glu. 2-Amino-4-phosphonobutyric acid has the same structure as L-glu except that it has a phosphate group in the position of the $\gamma-\mathrm{COOH}$ group of L-glu. Thus, the relative positions of three charged groups of these molecules can be identical with those of L-glu in certain conformations. It is conceivable that they could interact with $\mathrm{L}$-glu receptive sites as agonists and possibly as antagonists. In the Onchidium G-H cell, however, they were ineffective. It is hard to explain this result, although there are some possibilities. The relative positions of three charged groups have been emphasized so far, but it is also possible that the side chain other than the $\mathrm{COOH}$ group might play some role through hydrogen bonding when L-glu interacts with its receptor. If this kind of interaction exists between L-glu and its receptor, the relative position of the side chain is also important. This might explain why DL- $\alpha$-aminopimelic acid was ineffective on the L-glu response. The phosphate group of 2-amino-4-phosphonobutyric acid has a pKa 2 of 7.12. The negativity of this phosphate group is between monovalent and divalent at physiological $\mathrm{pH}$. This is stronger than that of L-glu's COOH group. This might be the cause of the present result.

The present experiment provides the evidence that the relative positions of three charged groups of L-glu are important to elicit the hyperpolarizing response in Onchidium G-H cells. Moreover, the relative position of the side chain and the strength of each charged group of Lglu may affect the interaction between L-glu and its receptive site.

\section{References}

Cull-Candy, S. G., J. F. Donnellan, R. W. James, and G. G. Lunt (1976) 2-Amino-4-phosphonobutyric acid as a glutamate antagonist on locust muscle. Nature (Lond.) 262: 408-409.

De Robertis, E. (1971) Molecular biology of synaptic receptors. Science 171: 963-971.

Dudel, J. (1977) Dose-response curve of glutamate applied by superfusion to crayfish muscle synapses. Pflügers Arch. 368: 49-54. 
Heidmann, T. and J. P. Changeux (1978) Structural and functional properties of the acetylcholine receptor protein in the purified and membrane-bound states. Annu. Rev. Biochem. 47: 317-357.

Kerkut, G. A., S. M. Piggott, and R. J. Walker (1975) The antagonist effect of alpha-aminopimelic acid on glutamate induced inhibitions of Helix neurons. Brain Res. 86: 139-143.

Lester, B. R., and E. J. Peck, Jr. (1979) Kinetic and pharmacologic characterization of gamma-aminobutyric acid receptive sites from mammalian brain. Brain Res. 161: 79-97.

Lowagie, C., and H. M. Gerschenfeld (1974) Glutamate antagonists at a crayfish neuromuscular junction. Nature (Lond.) 248: 533-535.

Nistri, A., and A. Constanti (1979) Pharmacological characterization of different types of GABA and glutamate receptors in vertebrates and invertebrates. Neurobiology 13: 117-235.

Oomura, Y., and T. Tomita (1961) Some observations concerning the end-plate potential. Tohoku J. Exp. Med. 73: 398415.

Oomura, Y., H. Ooyama, and M. Sawada (1974) Analysis of hyperpolarizations induced by glutamate and acetylcholine on Onchidium neurons. J. Physiol. (Lond.) 243: 321-341.

Oomura, Y., J. Maruhashi, N. Shimizu, and M. Kato (1979) GABA receptors and ionic channels in Onchidium neuron. Brain Res. Bull. 4: 178-180.

Oomura, Y., N. Shimizu, and J. Maruhashi (1982) Chemical structure of the GABA receptive membrane in Onchidium neurons studied by electrophysiological analysis. In Problems in GABA Research from Brain to Bacteria, Y. Okada and E. Roberts, eds., pp. 69-79, Excerpta Medica, Amsterdam.

Peper, K., F. Dreyer, and K. D. Müller (1975) Analysis of cooperativity of drug-receptor interaction by quantitative iontophoresis at frog motor end plates. Cold Spring Harbor Symp. Quant. Biol. 40: 187-192.

Piggott, S. M., G. A. Kerkut, and R. J. Walker (1975) Structureactivity studies on glutamate receptor sites of three identifiable neurons in the sub-oesophageal ganglia of Helix aspersa. Comp. Biochem. Physiol. 51C: 91-100.

Piggott, S. M., G. A. Kerkut, and R. J. Walker (1977) The actions of picrotoxin, strychnine, bicuculline and other convulsants and antagonists on the responses to acetylcholine, glutamic acid and gamma-aminobutyric acid on Helix neurons. Comp. Biochem. Physiol. 57C: 107-116.

Swan, J. E., and D. O. Carpenter (1975) Organization of receptors for neurotransmitters on Aplysia neurons. Nature 258: 751-754.

Takeuchi, A., and N. Takeuchi (1964) The effect on crayfish muscle of iontophoretically applied glutamate. J. Physiol. (Lond.) 170: 296-317.

Takeuchi, A., and N. Takeuchi (1972) Actions of transmitter substances on the neuromuscular junctions of vertebrates and invertebrates. J. Adv. Biophys. 3: 45-95.

Werman, R. (1969) An electrophysiological approach to drugreceptor mechanisms. Comp. Biochem. Physiol. 30: 997-1017. 